Check for updates

Cite this: RSC Adv., 2017, 7, 50753

\title{
Electrochemical properties of $\mathrm{NiCoO}_{2}$ synthesized by hydrothermal method
}

\author{
Xianwei Wang, (D)* Weixia Li, $\uparrow$ Xiaoer Wang, $\dagger$ Jingjie Zhang, $\uparrow$ Lingyun Sun, $\uparrow$ \\ Chang Gao, Jun Shang, Yanchun Hu and Qianqian Zhu
}

$\mathrm{NiCoO}_{2}$ microspheres were successfully synthesized via an easy hydrothermal method, followed by an annealing process at $350{ }^{\circ} \mathrm{C}$ under a nitrogen atmosphere. The X-ray diffraction results show that a single phase $\mathrm{NiCOO}_{2}$ was synthesized. The results of electrochemical measurements show that the $\mathrm{NiCOO}_{2}$ exhibits a high specific capacitance of 760 and $470 \mathrm{~F} \mathrm{~g}^{-1}$ at current densities of 1 and $16 \mathrm{~A} \mathrm{~g}^{-1}$, respectively, and the specific capacitance retention is $40.9 \%$ after 5000 cycles at the current density of $16 \mathrm{~A} \mathrm{~g}^{-1}$. This reveals the great potential of $\mathrm{NiCoO}_{2}$ as an electrode material for high-performance supercapacitors.

Received 14th September 2017 Accepted 26th October 2017

DOI: $10.1039 / c 7 r a 10232 a$

rsc.li/rsc-advances

higher electrical conductivity and specific capacitance than those of the single component nickel or cobalt oxides.

Recently, much research on the preparation and electro-

Clean energy conversion and storage devices have attracted great attention. Currently, supercapacitors, as a clean energy conversion and storage technology, have drawn intensive research attention in the past several years due to their high power densities, short charging times, safe operation mode and long cycle life. ${ }^{1-6}$ The electrode material, as an important component of a supercapacitor, plays a key role to gain high supercapacitor performances. ${ }^{7}$ Many kinds of materials have been considered as the electrode materials for supercapacitors, and they can be divided into three main kinds of electrode materials: ${ }^{8}$ carbonaceous materials, ${ }^{9}$ transition metal oxides ${ }^{10}$ and conducting polymer materials. ${ }^{11}$ However, many carbonaceous materials show low specific capacitance, and the conducting polymer materials exhibit poor electrical conductivity, leading to limited practical applications of these electrode materials for supercapacitors. ${ }^{12,13}$ Therefore, it is important to search for novel electrode materials, which show high electrical conductivity, large specific capacitance and high cyclic stability. Thus transition metal oxides as electrode materials have been widely investigated because of their alternative redox properties and high theoretical specific capacitance values. ${ }^{14}$ Especially, some transition metal oxides, such as $\mathrm{MnO}_{2},{ }^{15} \mathrm{Co}_{3} \mathrm{O}_{4}$ (ref. 16) and $\mathrm{NiO}^{17,18}$ have attracted great interest for use as supercapacitor electrode materials because of their low cost, natural abundance and environmental friendliness. Moreover, the nickel-cobalt binary metal oxides, such as $\mathrm{NiCO}_{2} \mathrm{O}_{4}$ (ref. 19 and 20) and $\mathrm{NiCoO}_{2}$ (ref. 21-23) have been also studied due to their

Laboratory of Functional Materials, College of Physics and Materials Science, Henan Normal University, Henan Key Laboratory of Photovoltaic Materials, Xinxiang 453007, China. E-mail: xwwang2000@163.com

$\dagger$ The four authors contributed equally to this work. chemical properties of $\mathrm{NiCo}_{2} \mathrm{O}_{4}$ has been reported. ${ }^{24-29}$ Especially, some artificial nanostructures show excellent properties. ${ }^{30-34}$ Two types of homogeneous $\mathrm{NiCO}_{2} \mathrm{O}_{4}$ nanosheet@ $\mathrm{NiCo}_{2} \mathrm{O}_{4}$ nanorod and heterogeneous $\mathrm{NiCo}_{2} \mathrm{O}_{4}$ nanosheet@NiO nanoflake hierarchical core-shell arrays were synthesized via facile solution methods followed by a simple thermal treatment, and high specific capacitances of 1925 and $2210 \mathrm{~F} \mathrm{~g}^{-1}$ were achieved by $\mathrm{NiCo}_{2} \mathrm{O}_{4} @ \mathrm{NiCo}_{2} \mathrm{O}_{4}$ and $\mathrm{NiCo}_{2}{ }^{-}$ $\mathrm{O}_{4} @ \mathrm{NiO}$ at $0.5 \mathrm{~A} \mathrm{~g}^{-1}$, respectively. ${ }^{35}$ However, research on $\mathrm{NiCoO}_{2}$ as an electrode material for supercapacitors is rare. ${ }^{2,19,21,36-39} \mathrm{Du}$ et al. prepared $\mathrm{NiCoO}_{2}$ single-crystalline nanoparticles with a specific capacitance of $184 \mathrm{~F} \mathrm{~g}^{-1}$ at $1 \mathrm{~A} \mathrm{~g}^{-1} \cdot{ }^{40} \mathrm{NiCoO}_{2}$ was synthesized based on the templates and used for supercapacitors. ${ }^{2,21,36-39}$

In this study, we successfully synthesized micro-spheres $\mathrm{NiCoO}_{2}$ by a simple hydrothermal method, followed by calcining at $350{ }^{\circ} \mathrm{C}$ under a nitrogen atmosphere. The $\mathrm{NiCoO}_{2}$ exhibited a specific capacitance of $760 \mathrm{~F} \mathrm{~g}^{-1}$ at a current density of $1 \mathrm{~A} \mathrm{~g}^{-1}$ in three electrode measurements. Especially, the specific capacitance retains approximately $40.9 \%$ of its maximum value after 5000 cycles at the current density of $16 \mathrm{~A} \mathrm{~g}^{-1}$.

\section{Experimental}

\subsection{Preparation of $\mathrm{NiCoO}_{2}$}

$0.474 \mathrm{~g} \mathrm{NiCl} 2 \cdot 6 \mathrm{H}_{2} \mathrm{O}, 0.474 \mathrm{~g} \mathrm{CoCl} \cdot 6 \mathrm{H}_{2} \mathrm{O}$ and $2.0 \mathrm{~g}$ urea were dissolved in $30 \mathrm{~mL}$ distilled water with magnetic stirring for $30 \mathrm{~min}$ at room temperature to form a clear solution. Then, the obtained solution was transferred into a $50 \mathrm{~mL}$ Teflon-lined stainless steel autoclave and maintained at $120{ }^{\circ} \mathrm{C}$ for $12 \mathrm{~h}$. 
After cooling down to room temperature, the precipitate was centrifuged and washed with distilled water and ethanol. Then, the obtained precipitate was dried at $60{ }^{\circ} \mathrm{C}$ for $6 \mathrm{~h}$. Finally, the dried precipitate was calcined at $350{ }^{\circ} \mathrm{C}$ for $3 \mathrm{~h}$ under nitrogen atmosphere.

\subsection{Characterization}

The crystal structure was characterized by X-ray diffraction (XRD, Bruker D8 discover) using $\mathrm{Cu} \mathrm{K} \alpha$ radiation at $40 \mathrm{kV}$ and $40 \mathrm{~mA}$. The morphology was examined by field emission scanning electron microscopy (FE-SEM, Zeiss SUPRA 40) and transmission electron microscopy (TEM, JEM-2100). X-ray photoelectron spectroscopy (XPS, ESCALAB250Xi) was used to characterize valence states of the sample. The specific surface area and pore size distribution of the sample were performed by Brunauer-Emmett-Teller (BET) nitrogen adsorption-desorption and Barrett-Joyner-Halenda (BJH) methods (Autosorb-iQ). The electrochemical characterizations were carried out in a CS 350 electrochemical workstation (CorrTest, Wuhan) at room temperature using $3 \mathrm{M} \mathrm{KOH}$ solution as electrolyte solution. A three-electrode system was used in the measurement. Nickel foam coated with electroactive materials was used as the working electrode. Platinum and $\mathrm{Hg} / \mathrm{HgO}$ electrode $(1 \mathrm{M} \mathrm{NaOH}$ solution) were served as the counter electrode and the reference electrode, respectively. The working electrode was fabricated by mixing the as-prepared products, carbon blacks and polytetrafluoroethylene (PTFE) with a weight ratio of $70: 20: 10$ to form homogeneous paste, which was coated onto nickel foam with the area of $1 \mathrm{~cm} \times 1 \mathrm{~cm}$. After drying in a vacuum oven at $50{ }^{\circ} \mathrm{C}$ for $5 \mathrm{~h}$ to remove the solvent, the nickel foam was then pressed at $10 \mathrm{MPa}$ for $2 \mathrm{~min}$ by bead machine. The mass of active materials loading on the nickel foam with the area of $1 \mathrm{~cm} \times$ $1 \mathrm{~cm}$ was about 3-5 $\mathrm{mg}$.

Cyclic voltammetry (CV) tests were performed from $-0.1 \mathrm{~V}$ to $0.8 \mathrm{~V}$ at a scan rate of $5,10,20,40,60$ and $100 \mathrm{mV} \mathrm{s}^{-1}$. Galvanostatic charge-discharge (GCD) tests were performed at a current density of $1,2,4,6,10$ and $16 \mathrm{~A} \mathrm{~g}^{-1}$ with the potential window from $0 \mathrm{~V}$ to $0.55 \mathrm{~V}$. Electrochemical impedance spectroscopy (EIS) measurements were measured at a frequency range from $10^{5} \mathrm{~Hz}$ to $0.01 \mathrm{~Hz}$ with an amplitude of $3 \mathrm{mV}$.

\section{Results and discussion}

\subsection{Structure characterization}

Fig. 1 shows the XRD pattern of the samples calcined at $350{ }^{\circ} \mathrm{C}$ under nitrogen atmosphere. The diffraction pattern showed six peaks at $36.80^{\circ}, 42.82^{\circ}, 61.79^{\circ}, 73.99^{\circ}, 77.99^{\circ}$ and $93.22^{\circ}$, corresponding to (111), (200), (220), (311), (222) and (400) of $\mathrm{NiCoO}_{2}$ phase (JCPDS no. 10-0188), respectively. No impurity peaks were observed in the pattern, confirming the single pure phase of the obtained product.

The elemental composition and the valence states of the $\mathrm{Ni}$ and Co in the sample were investigated by XPS, and the results are presented in Fig. 2. Fig. 2(a) shows the survey spectrum of the sample. It clearly showed the peaks of $\mathrm{Ni}, \mathrm{Co}, \mathrm{O}$ and $\mathrm{C}$ elements. The $\mathrm{C}$ element can be attributed to the exposure of

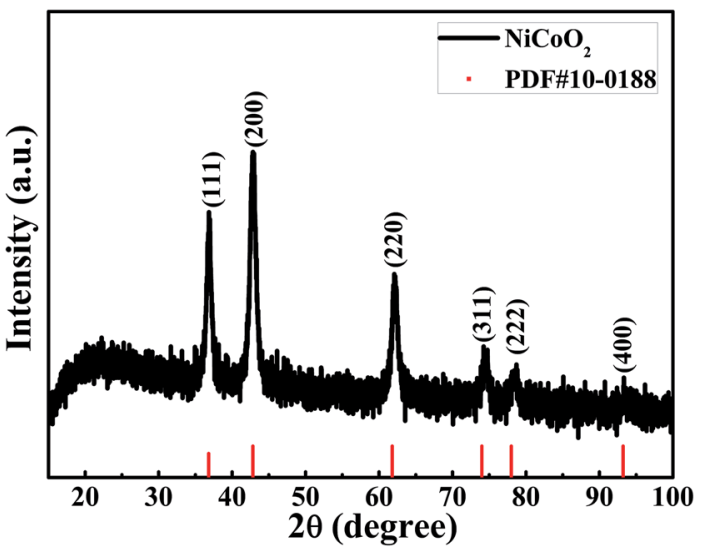

Fig. 1 XRD patterns of the $\mathrm{NiCoO}_{2}$ samples

air. Fig. 2(b) shows the spectrum of Ni 2p, which was composed of two spin-orbit doublets and two shakeup satellites. As reported in ref. 41 there are four easily discernible features in $\mathrm{Ni}$ $2 \mathrm{p}$ spectrum, they are the $\mathrm{Ni} 2 \mathrm{p}_{3 / 2}$ main peak and its satellite, and the $\mathrm{Ni} 2 \mathrm{p}_{1 / 2}$ main peak and its satellite, respectively. The fitting peaks at 854.2 and $856.0 \mathrm{eV}$ are corresponding to $\mathrm{Ni} 2 \mathrm{p}_{3 / 2}$, whereas the peaks at 871.8 and $873.7 \mathrm{eV}$ are corresponding to $\mathrm{Ni}$ $2 \mathrm{p}_{1 / 2}$. The peaks Sat.1 at $861.2 \mathrm{eV}$ and Sat.2 at $879.1 \mathrm{eV}$ are ascribed to the two shakeup satellites of Ni main peaks. The peak of $\mathrm{Ni} 2 \mathrm{p}_{3 / 2}$ at $854.2 \mathrm{eV}$ is ascribed to local screening from lattice oxygen adjacent to the $\mathrm{Ni} 2 \mathrm{p}$ core hole. ${ }^{\mathbf{4 1}}$ And the existence of peak at $856.0 \mathrm{eV}$ is prevalent, suggesting a higher hydroxylation of $\mathrm{NiO}$ in the composite oxide surface, ${ }^{42}$ which can be further confirmed by the $\mathrm{O} 1 \mathrm{~s}$ spectrum. The binding energy peaks of $\mathrm{Ni} 2 \mathrm{p}_{1 / 2}$ are consistent with that of $\mathrm{Ni} 2 \mathrm{p}_{3 / 2}$. The fitting results show the appropriate binding energies of $\mathrm{Ni} 2 \mathrm{p}$, indicating that the divalent oxide state of $\mathrm{Ni}$ was existed in sample. ${ }^{41}$ Fig. 2(c) shows the core level spectrum of Co 2 p. The fitting peak at $780.1 \mathrm{eV}$ and $797.0 \mathrm{eV}$ is corresponding to Co $2 \mathrm{p}_{3 / 2}$ and Co $2 \mathrm{p}_{1 / 2}$, respectively, and these two peaks could be indexed to $\mathrm{Co}^{2+} \cdot{ }^{\mathbf{4 3 4} 44}$ In addition, the shake-up satellite peak Sat.1 located at $785.8 \mathrm{eV}$ has a separation energy of $\sim 5.2 \mathrm{eV}$ with Co $2 \mathrm{p}_{3 / 2}$ at $780.1 \mathrm{eV}$, while the shake-up satellite peak Sat.2 located at $802.2 \mathrm{eV}$ has a separation energy of $\sim 5.2 \mathrm{eV}$ with Co $2 \mathrm{p}_{1 / 2}$ at $797.0 \mathrm{eV}$. The energy gap between the Co $2 \mathrm{p}$ main peak and the satellite peaks is related to the oxidation states, and the energy gaps are about $6.0 \mathrm{eV}$ and 9-10 eV for $\mathrm{Co}^{2+}$ and $\mathrm{Co}^{3+} .^{45}$ The results prove that the divalent oxide state of Co was existed in sample. The high resolution spectrum for $O$ 1s peak in Fig. 2(d) decomposes into two oxygen contributions. The fitting peak located at $529.4 \mathrm{eV}\left(\mathrm{O}_{1}\right)$ are typical of the metal-oxygen bonds $(\mathrm{M}=\mathrm{Ni}$ or $\mathrm{Co}) .{ }^{46}$ The component $\mathrm{O}_{2}$ located at $531.1 \mathrm{eV}$ indicates the presence of surface hydroxyl groups. ${ }^{\mathbf{4 1 , 4 2 , 4 7 , 4 8}}$ According to the XPS analysis, these results show that the $\mathrm{NiCoO}_{2}$ samples contain $\mathrm{Ni}^{2+}$ and $\mathrm{Co}^{2+}$, the atomic percentage of $\mathrm{Ni}$, Co and $\mathrm{O}$ is $23.11,23.49$ and $53.4 \%$, respectively. The calculated atomic ratio of $\mathrm{Ni}$ to $\mathrm{Co}$ and $\mathrm{O}$ is close to $1: 1: 2$, which is on the verge of the stoichiometry of $\mathrm{NiCoO}_{2}$.

The morphologies of $\mathrm{NiCoO}_{2}$ sample were characterized by SEM and TEM. As shown in Fig. 3(a), $\mathrm{NiCoO}_{2}$ sample showed 

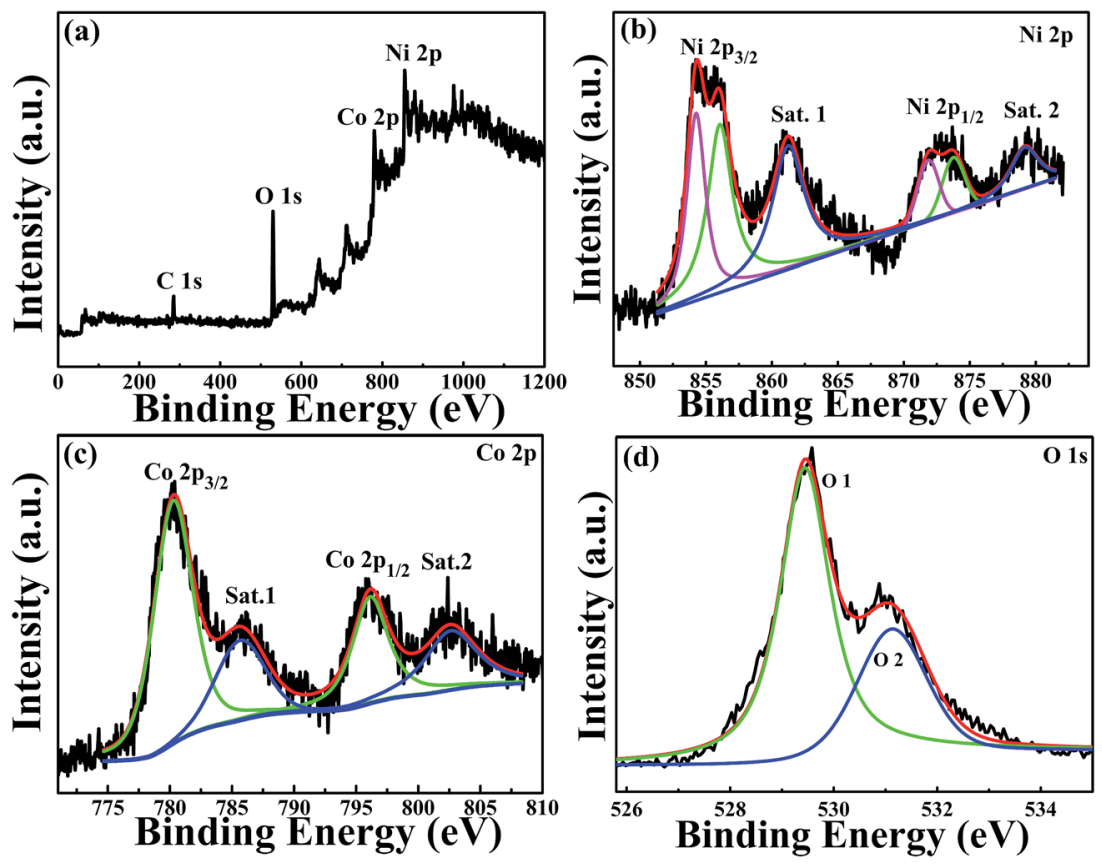

Fig. 2 XPS spectrum of (a) survey spectrum, (b) Ni 2 p spectrum, (c) Co $2 p$ spectrum and (d) $\mathrm{O} 1 \mathrm{~s}$ spectrum for the $\mathrm{NiCoO}_{2}$ samples.

the microspheres with different size in the low-magnification SEM image of sample. The diameter of the sphere varied from $1 \mu \mathrm{m}$ to $6 \mu \mathrm{m}$. Furthermore, the microspheres are assembled by a large amount of nanowires according to the highmagnification SEM images as shown in Fig. 3(b). To identify the distribution of element in sample, the element mappings of $\mathrm{Ni}, \mathrm{Co}$ and $\mathrm{O}$ were examined by energy dispersive spectroscopy (EDS). Fig. 3(c) is a typical microsphere of sample, and the element mapping of $\mathrm{Ni}, \mathrm{Co}$ and $\mathrm{O}$ were included. It can be seen clearly that $\mathrm{Ni}$, Co and $\mathrm{O}$ elements are uniformly distributed in the microsphere, and that the ratio of three elements is around $1: 1: 2$, which corresponded with the composition of $\mathrm{NiCoO}_{2}$. Fig. 3(d)-(f) show TEM images of the samples. Pompon shape was observed in samples, and this is consistent with the morphology results of SEM. The high-magnification TEM image revealed that the nanowires in pompon were composed of nanoparticles. Fig. 3(e) selected area electron diffraction (SAED) pattern showed ring patters, which revealed that the nanowire in pompon has a polycrystalline structure. These rings could be assigned to the (111), (200), (220), (311), (222) and (400) crystal planes of $\mathrm{NiCoO}_{2}$, which is consistent with the observation of $\mathrm{XRD}$ results. The lattice spacing of $0.208 \mathrm{~nm}$ is attributed to the (200) crystal plane of $\mathrm{NiCoO}_{2}$ sample, as shown in the HRTEM image of Fig. 3(f).

The results of XRD, TEM, EDS and XPS confirm that single pure phase of $\mathrm{NiCoO}_{2}$ with pompon shape was obtained in present research, and the pompon with different diameter is composed of nanowires, which were composed of $\mathrm{NiCoO}_{2}$ nanoparticles.

The porous structure of sample was evaluated by BrunauerEmmett-Teller (BET) $\mathrm{N}_{2}$-adsorption-desorption analysis. The $\mathrm{N}_{2}$ adsorption-desorption isotherm and pore size distribution were shown in Fig. 4. The BET specific surface area is about $88.3 \mathrm{~m}^{2} \mathrm{~g}^{-1}$. As can be seen from Fig. 4, the typical type IV hysteresis loop can be observed in the region of $P / P_{0}$ from 0.6 to 1.0 , which illustrates the existence of a mesoporous structure in sample. ${ }^{43,49}$ The pore size distributions, which were shown in insert of Fig. 4, were calculated by the Barrett-Joyner-Halenda (BJH) method. It shows that sharp peaks are located at $2.7 \mathrm{~nm}$ and $11.0 \mathrm{~nm}$, illustrating a few mesoporous were presented in $\mathrm{NiCoO}_{2}$ samples. Such results are consistent with the results of SEM and TEM results. The rich internal mesoporous structure could increase the contact area between electrode and electrolyte, leading to more sufficient active sites for redox reaction and efficient transport of electrons and ions. ${ }^{43,49}$ Therefore, the high surface area and mesoporous structure of $\mathrm{NiCoO}_{2}$ sample are benefic for application in supercapacitor. ${ }^{43,49,50}$

\subsection{Electrochemical characterization}

Fig. 5(a) shows the CV curves of the $\mathrm{NiCoO}_{2}$ micro pompon at different scan rates from $5 \mathrm{mV} \mathrm{s}^{-1}$ to $100 \mathrm{mV} \mathrm{s}^{-1}$ within potential range from $-0.1 \mathrm{~V}$ to $0.8 \mathrm{~V}(v s$. $\mathrm{Hg} / \mathrm{HgO})$ in $3 \mathrm{M} \mathrm{KOH}$ solution. All the curves show typical faradic reaction peaks, corresponding to the $\mathrm{M}-\mathrm{O} / \mathrm{M}-\mathrm{O}-\mathrm{OH}$ ( $\mathrm{M}$ represents $\mathrm{Ni}$ and $\mathrm{Co}$ ions). ${ }^{39,51,52}$ With the increase of scan rate, a shift toward higher and lower potentials was observed for the oxidation and reduction peaks, respectively. As shown in inset of Fig. 5(b), this shift leading to the increase of the potential difference between redox peaks. It indicated that the irreversible degree of the quasi-reversible reaction increased with the increase of scan rate. The shift is mainly related to the internal resistance of the electrode and the polarization caused by high scan rate..$^{53}$

The specific capacitance of samples can be calculated by using the following equation: 

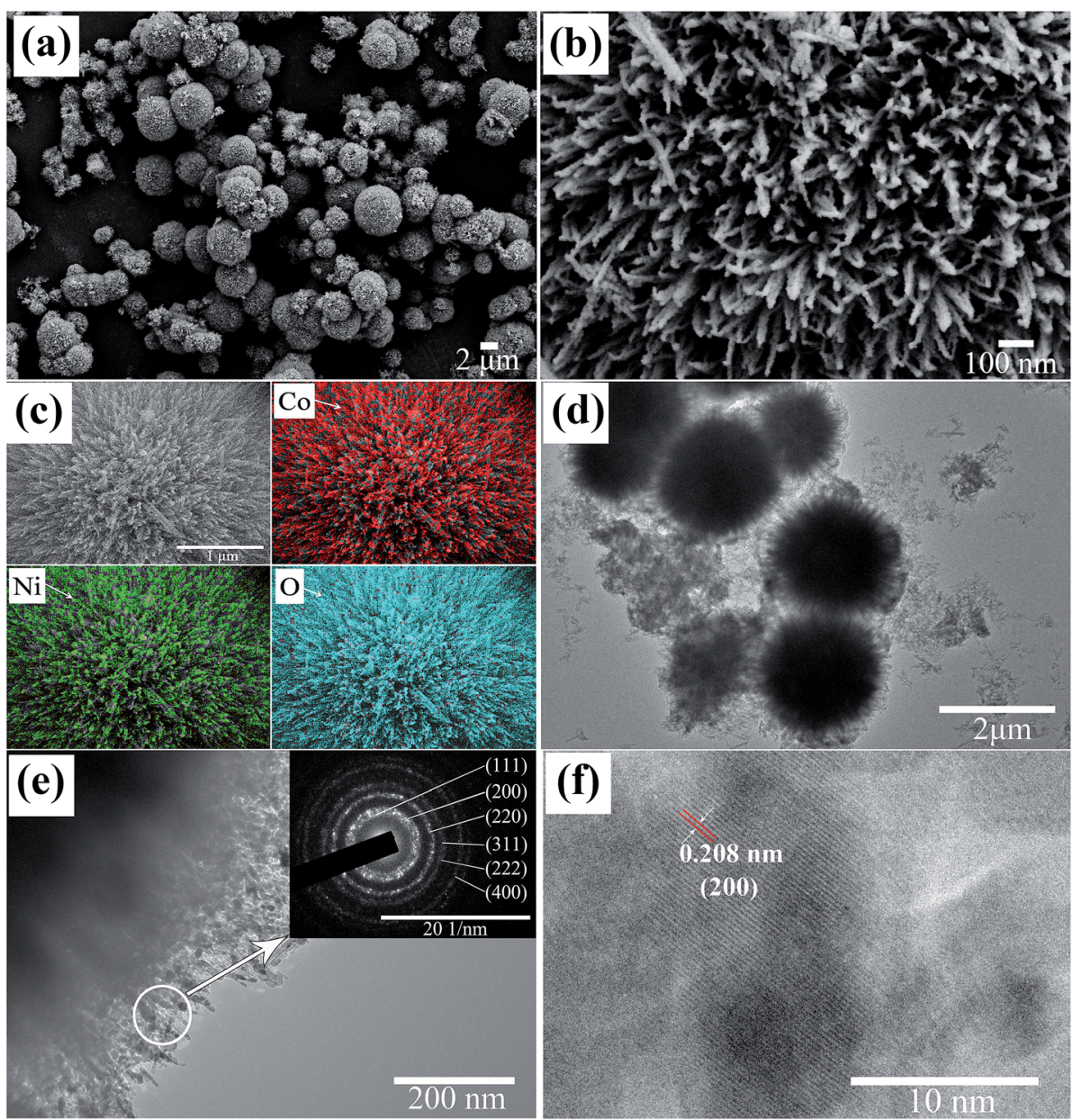

Fig. 3 (a) Low-magnification SEM, (b) high-magnification SEM, (c) energy dispersive spectroscopy (EDS) element mapping images of the NiCoO 2 sample and the Ni, Co and O distribution, (d) low-magnification TEM, (e) high-magnification TEM (inset showing the selected area electron diffraction ring) and (f) HRTEM image of $\mathrm{NiCOO}_{2}$ sample.

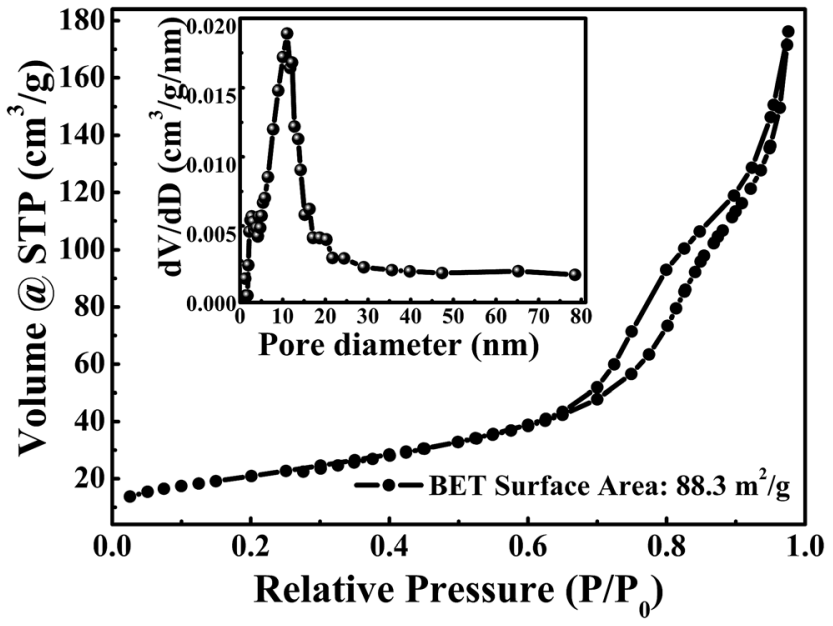

Fig. 4 The $\mathrm{N} 2$ adsorption-desorption isotherms of the $\mathrm{NiCoO}_{2}$. The inset is the pore size distributions are calculated by the Barrett-Joyner-Halenda $(\mathrm{BJH})$ method.

$$
C_{\mathrm{sp}}=\frac{\int I_{(V)} \mathrm{d} V}{2 m \times v \times \Delta V},
$$

where $C_{\mathrm{sp}}\left(\mathrm{F} \mathrm{g}^{-1}\right)$ is the specific capacitance, $I_{(V)}(\mathrm{A})$ is cathodic current, $m(\mathrm{~g})$ is the mass of the active material used to prepare the electrode, $v\left(\mathrm{mV} \mathrm{s}^{-1}\right)$ is the potential scan rate, and $V(\mathrm{~V})$ is the sweep potential window. Fig. 5(b) presents specific capacitance dependent on the potential scan rate. The specific capacitance decreased with the increase of scan rate. The specific capacitance was $1461 \mathrm{~F} \mathrm{~g}^{-1}$ at a scan rate of $5 \mathrm{mV} \mathrm{s}^{-1}$, and it decreases sharply to be $924 \mathrm{~F} \mathrm{~g}^{-1}$ at a scan rate of $10 \mathrm{mV} \mathrm{s}^{-1}$, then the capacitance decreases slightly with the continue increase of scan rates. Anion of $\mathrm{OH}^{-}$could reach the electro-active sites adequately for slow scan rate, but only the electrode surface could be utilized to store charges during the electrochemical reaction process for fast scan rate, leading to the decrease of specific capacitance with increase of scan rate. ${ }^{42}$

As shown in Fig. 6(a), the GCD curves of $\mathrm{NiCoO}_{2}$ electrodes were measured at different current densities of $1,2,4,6,10$ and $16 \mathrm{~A} \mathrm{~g}^{-1}$ in $3 \mathrm{M} \mathrm{KOH}$ solution in the voltage range of $0-0.55 \mathrm{~V}$ (vs. $\mathrm{Hg} / \mathrm{HgO}$ ). The nonlinear curve indicated the 

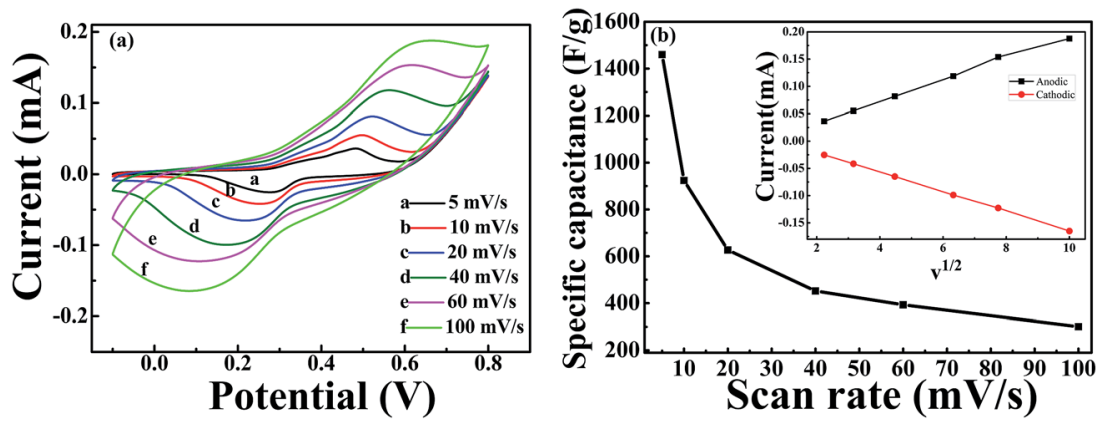

Fig. 5 (a) CV curves under different scan rates of 5, 10, 20,40,60, $100 \mathrm{mV} \mathrm{s}^{-1}$ for $\mathrm{NiCoO}_{2}$ samples in the potential window ranged from -0.1 to $0.8 \mathrm{~V}$; (b) the specific capacitance of $\mathrm{NiCoO}_{2}$ sample under different scan rates of 5, 10,20,40,60 and $100 \mathrm{mV} \mathrm{s}^{-1}$. The inset in (b) is the plots of anodic and cathodic peak current against the square root of the scan rate.
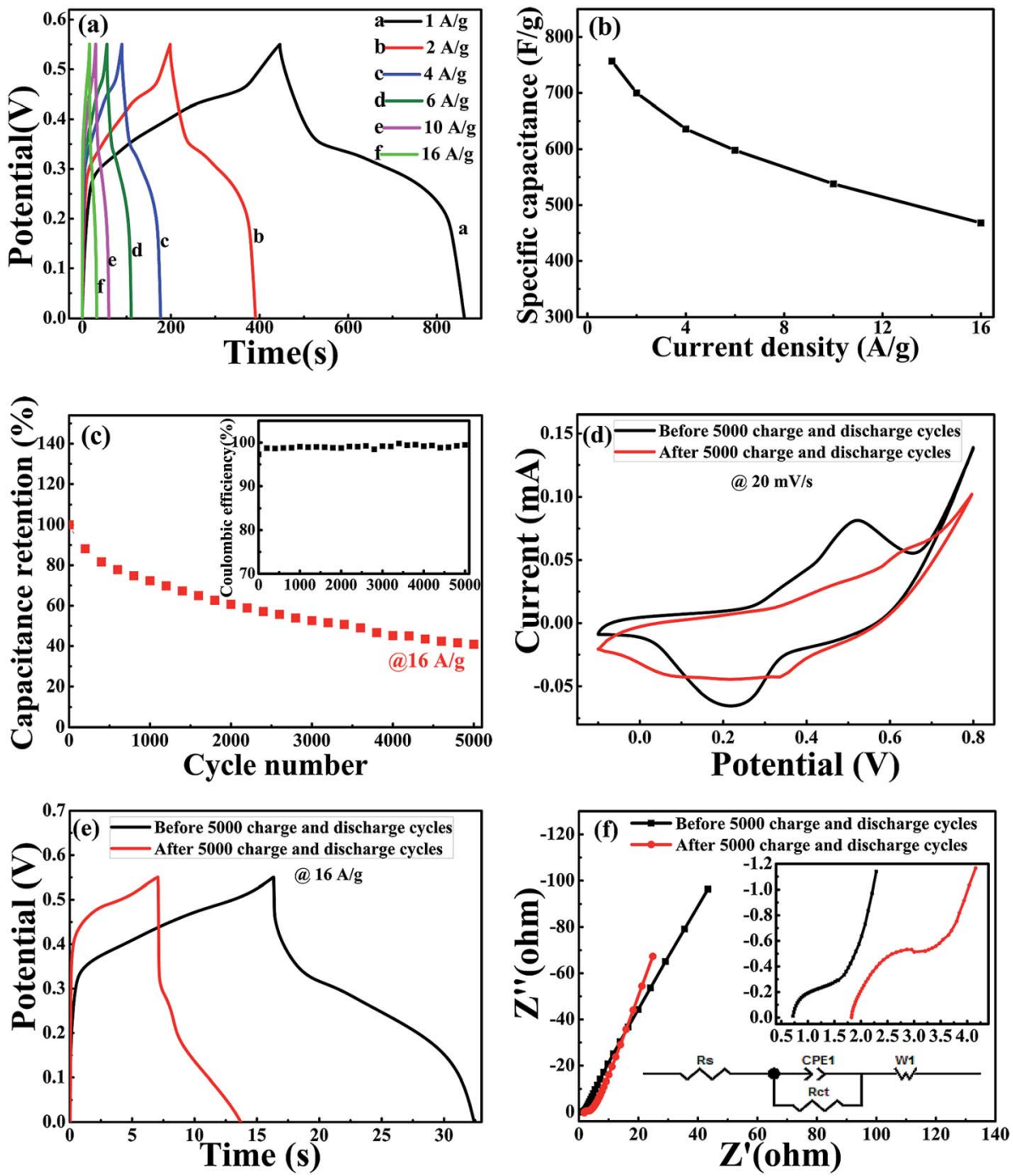

Fig. 6 (a) Galvanostatic charge-discharge curves are within the potential range of 0 to $0.55 \mathrm{~V}$ at various current densities from $1 \mathrm{~A} \mathrm{~g}^{-1}$ to $16 \mathrm{~A} \mathrm{~g}^{-1}$, (b) specific capacitance at various current densities from $1 \mathrm{~A} \mathrm{~g} \mathrm{~g}^{-1}$ to $16 \mathrm{~A} \mathrm{~g}^{-1}$. (c) Cycling performance of the $\mathrm{NiCoO} 2$ electrode at $16 \mathrm{~A} \mathrm{~g}^{-1}$, the insert shows the corresponding coulombic efficiency of $\mathrm{NiCoO}_{2}$ during cycling test. (d) $\mathrm{CV}$ and (e) $\mathrm{GCD}$ curves of $\mathrm{NiCoO}_{2}$ electrode before and after 5000 charge-discharge cycles. (f) Nyquist plots obtained for $\mathrm{NiCOO}_{2}$ samples at the frequency ranging from $0.01 \mathrm{~Hz}$ to $100 \mathrm{KHz}$ in $3 \mathrm{M} \mathrm{KOH}$. Insets: the local amplification of the Nyquist plots at high-frequency. 
pseudocapacitance behavior, and the potential plateaus corresponded with the redox reaction, which was consistent with the CV curves in Fig. 5(a). The specific capacitance could be calculated from the galvanostatic charge-discharge curves according to the following equation:

$$
C_{\mathrm{m}}=\frac{I \times \Delta t}{m \times \Delta V},
$$

where $C_{\mathrm{m}}\left(\mathrm{F} \mathrm{g} \mathrm{g}^{-1}\right)$ is the specific capacitance, $I$ (A) refers to the current density used for the charge-discharge measurements, $\Delta t$ (s) refers to the time elapsed for the discharge cycle in the potential window, $\Delta V(\mathrm{~V})$ represents the voltage interval of the discharge measurement, and $m(\mathrm{~g})$ denotes the mass of active material in the working electrode. Fig. 6(b) shows the dependence of the specific capacitance on the current density. The specific capacitance decreased with the increase of current density, which could be attributed to the reduce of effective contact between ions and electroactive sites of electrode at high current rate. ${ }^{54}$ The specific capacitance could be calculated to $760,700,636,598,538$ and $470 \mathrm{~F} \mathrm{~g}^{-1}$ at various current densities from $1,2,4,6,10$ and $16 \mathrm{~A} \mathrm{~g}^{-1}$, respectively. The specific capacitance showed small loss under the current density increasing, and it was only $38 \%$ when the current density increased from 1 to $16 \mathrm{~A} \mathrm{~g}^{-1}$. The high performance at high current density could be attributed to the excellent microstructure. The pompon assembled with nanowire facilitates ion permeability, and the pompon could be served as ion reservoir. The diffusion distance of electrolyte to electro active sites is decreased largely, as is beneficial for the rapid redox reaction at high current density. ${ }^{\mathbf{4 3} 49}$ A cycle stability of $\mathrm{NiCoO}_{2}$ electrode was also evaluated by the repeated charge-discharge measurement at $16 \mathrm{~A} \mathrm{~g}^{-1}$ for 5000 cycles. As shown in Fig. 6(c), the specific capacitance of the samples decreased slowly, and approximate $40.9 \%$ of the initial specific capacitance was retained after 5000 cycles, indicating fine long-cycle stability in $\mathrm{NiCoO}_{2}$ sample with pompon structure. The insert in Fig. 6(c) is the coulombic efficiencies of $\mathrm{NiCoO}_{2}$ during the 5000 chargedischarge cycles, it was remained around $97.3 \%$ to $99.8 \%$. The fine long-term cycle properties might attributed to the low internal electron transport resistance during the chargedischarge process. ${ }^{55}$ Furthermore, the $\mathrm{CV}$ curves at $20 \mathrm{mV} \mathrm{s}^{-1}$ and GCD curves at $16 \mathrm{~A} \mathrm{~g}^{-1}$ of $\mathrm{NiCoO}_{2}$ electrode after 5000 charge-discharge cycles were investigated. Comparing to that before 5000 cycles, the electrode shows weaken electrochemical properties, which can be seen in Fig. 6(d) and (e). The CV and GCD curves all show around $40 \%$ retention of specific capacitance after the $5000^{\text {th }}$ cycle.

The electrochemical impedance spectroscopy (EIS) was used to evaluate the electrical resistance responses of the $\mathrm{NiCoO}_{2}$ electrode materials. Fig. 6(f) shows the Nyquist plots of $\mathrm{NiCoO}_{2}$ before and after 5000 charge-discharge cycle measurement. The EIS spectra could be fitted according to the equivalent circuit diagram inserted in Fig. 6(f). $R_{\mathrm{S}}$ is the internal resistances of the electrode, including the total resistances of the electrode resistance, the bulk electrolyte resistance and the resistance at electrolyte-electrode interface, ${ }^{56}$ and $R_{\mathrm{ct}}$ is the charge-transfer resistances, corresponding to the semicircle in the high- frequency region. ${ }^{57,58}$ The fitted $R_{\mathrm{s}}$ and $R_{\mathrm{ct}}$ values are very small, and the low values are beneficial for long-cycle stability. After 5000 cycles, the $R_{\mathrm{s}}$ value increased from $0.71 \Omega$ to $1.81 \Omega$, and the $R_{\text {ct }}$ value increased from $0.45 \Omega$ to $0.84 \Omega$. The linear part at low frequency region representative of the typical Warburg resistance $\left(W_{1}\right){ }^{59}$ and the $\mathrm{CPE}_{1}$ represents double layer capacitance caused by the rough surface of $\mathrm{NiCoO}_{2}$ samples and inhomogeneous distribution of active sites. ${ }^{37}$ For an ideal supercapacitor, the Nyqusit plot should be a vertical line at a low frequency, which is parallel to the imaginary impedance axis. ${ }^{34}$ The slope of line increased from 2.32 to 2.67 . The curve becomes more vertical in the low-frequency range after 5000 cycles, indicating that the electro active material becomes more capacitive after long-term cycling. ${ }^{60}$ EIS results further indicate that $\mathrm{NiCoO}_{2}$ sample with micro pompon structure show low internal and charge-transfer resistance, and stable electrochemical stability.

\section{Conclusions}

In summary, $\mathrm{NiCoO}_{2}$ micro pompon sample were successfully prepared by a facile hydrothermal method. The micro pompon was assembled with nanowire, and the nanowire is composed with $\mathrm{NiCoO}_{2}$ nanoparticles. Electrochemical measurement results display that the micro-sphere $\mathrm{NiCoO}_{2}$ materials have the remarkable electrochemical behavior. The specific capacitance was $760 \mathrm{~F} \mathrm{~g}^{-1}$ at a current density of $1 \mathrm{~A} \mathrm{~g}^{-1}$. The specific capacitance showed small loss under the current density increasing, and it was only $38 \%$ when the current density increased from 1 to $16 \mathrm{~A} \mathrm{~g}^{-1}$. In addition, the $\mathrm{NiCoO}_{2}$ micro pompon with low internal and charge-transfer resistance exhibited fine long-cycle stability, around $40.9 \%$ of its initial specific capacitance was maintained after 5000 chargedischarge cycles. The excellent electrochemical properties make the $\mathrm{NiCoO}_{2}$ micro pompon sample be the promising candidate electrodes materials of supercapacitor in practical applications.

\section{Conflicts of interest}

There are no conflicts to declare.

\section{Acknowledgements}

This work has been supported by the National Natural Science Foundation of China (No. 51402091, No. 51601059, No. 11304082 and No. 11404102), the scientific research foundation for new introduced doctors in Henan Normal University (No. 11114), and the National University Student Innovation Program (No. 201410476037).

\section{References}

1 F. Béguin, V. Presser, A. Balducci and E. Frackowiak, $A d v$. Mater., 2014, 26, 2219-2251.

2 X. Xu, H. Zhao, J. K. Zhou, R. Xue and J. Gao, J. Power Sources, 2016, 329, 238-246. 
3 W. Chen, C. Xia and H. N. Alshareef, ACS Nano, 2014, 8, 9531-9541.

4 M. Jana, S. Saha, P. Samanta, N. C. Murmu, N. H. Kim, T. Kuila and J. H. Lee, J. Mater. Chem. A, 2016, 4, 2188-2197. 5 D. Li, Y. Gong, M. Wang and C. Pan, Nano-Micro Lett., 2017, 9, 16.

6 J. Ji, L. L. Zhang, H. Ji, Y. Li, X. Zhao, X. Bai, X. Fan, F. Zhang and R. S. Ruoff, ACS Nano, 2013, 7, 6237-6243.

7 X. L. Guo, X. Y. Liu, X. D. Hao, S. J. Zhu, F. Dong, Z. Q. Wen and Y. X. Zhang, Electrochim. Acta, 2016, 194, 179-186.

8 X. Yang, K. Xu, R. Zou and J. Hu, Nano-Micro Lett., 2016, 8, 1-8. 9 L. L. Zhang and X. S. Zhao, Chem. Soc. Rev., 2009, 38, 25202531.

10 H. B. Wu, H. Pang and X. W. Lou, Energy Environ. Sci., 2013, 6, 3619-3626.

11 L. Nyholm, G. NyströM, A. Mihranyan and M. StrøMme, Adv. Mater., 2011, 23, 3751-3769.

12 M. Jana, S. Saha, P. Samanta, N. C. Murmu, J. H. Lee and T. Kuila, Mater. Chem. Phys., 2015, 151, 72-80.

13 P. Simon and Y. Gogotsi, Nat. Mater., 2008, 7, 845-854.

14 H. Gao, G. Wang, M. Yang, L. Tan and J. Yu, Nanotechnology, 2012, 23, 015607.

15 Y. Sun, Z. Fang, C. Wang, K. R. Ariyawansha, A. Zhou and H. Duan, Nanoscale, 2015, 7, 7790-7801.

16 L. Hou, C. Yuan, L. Yang, L. Shen, F. Zhang and X. Zhang, RSC Adv., 2011, 1, 1521-1526.

17 G. Chen, H. Guan, C. Dong, X. Xiao and Y. Wang, J. Phys. Chem. Solids, 2016, 98, 209-219.

18 Q. Sun and S. Bao, Nano-Micro Lett., 2013, 5, 289-295.

19 Y. Zhang and Z. Guo, Mater. Chem. Phys., 2016, 171, 208-215.

20 M. Kuang, Y. X. Zhang, T. T. Li, K. F. Li, S. M. Zhang, G. Li and W. Zhang, J. Power Sources, 2015, 283, 270-278.

21 X. Xu, H. Zhou, S. Ding, J. Li, B. Li and D. Yu, J. Power Sources, 2014, 267, 641-647.

22 X. Xu, B. Dong, S. Ding, C. Xiao and D. Yu, J. Mater. Chem. A, 2014, 2, 13069-13074.

23 X. Xu, S. Chen, C. Xiao, K. Xi, C. Guo, S. Guo, S. Ding, D. Yu and R. V. Kumar, ACS Appl. Mater. Interfaces, 2016, 8, 60046010.

24 Q. Wang, X. Wang, B. Liu, G. Yu, X. Hou, D. Chen and G. Shen, J. Mater. Chem. A, 2013, 1, 2468-2473.

25 Y. Li, M. Zhang, D. Pan, Y. Wang, J. Xie, Z. Yan and J. Jing, J. Alloys Compd., 2017, 722, 903-912.

26 W. Jiang, F. Hu, S. Yao, Z. Sun and X. Wu, Mater. Res. Bull., 2017, 93, 303-309.

27 M. Yao, N. Wang, J. Yin and W. Hu, J. Mater. Sci.: Mater. Electron., 2017, 28, 11119-11124.

28 K. Xu, X. Yang, J. Yang and J. Hu, J. Alloys Compd., 2017, 700, 247-251.

29 S. Han, L. Lin, K. Zhang, L. Luo, X. Peng and N. Hu, Mater. Lett., 2017, 193, 89-92.

30 M. Shahraki, S. Elyasi, H. Heydari and N. Dalir, J. Electron. Mater., 2017, 46, 1-7.

31 Y. Zhang, Y. Zhang, D. Zhang and L. Sun, Dalton Trans., 2017, 46, 9457-9465.

32 H. Xin, Z. Xu, Y. Liu, W. Li and Z. Hu, J. Alloys Compd., 2017, 711, 670-676.
33 T. Han, Int. J. Electrochem. Sci., 2017, 12, 4724-4732.

$34 \mathrm{~V}$. Venkatachalam, A. Alsalme, A. Alghamdi and R. Jayavel, Ionics, 2017, 23, 977-984.

35 W. Zhou, D. Kong, X. Jia, C. Ding, C. Cheng and G. Wen, J. Mater. Chem. A, 2014, 2, 6310-6315.

36 X. W. Wang, X. E. Wang, Y. P. Liu, Y. Y. Kong, L. Y. Sun, Y. C. $\mathrm{Hu}$ and Q. Q. Zhu, J. Mater. Sci.: Mater. Electron., 2017, 1-7, DOI: 10.1007/s10854-017-7364-x.

37 Y. Chen, Y. Xu, J. Wei, L. Tan and J. Yu, J. Mater. Chem. A, 2015, 3, 7121-7131.

38 Y. Ma, P. Liu, Q. Liu, Z. Chen, D. Qu and J. Shi, RSC Adv., 2016, 6, 74643-74648.

39 J. Liang, K. Xi, G. Tan, S. Chen, T. Zhao, P. R. Coxon, H. K. Kim, S. Ding, Y. Yang and R. V. Kumar, Nano Energy, 2016, 27, 457-465.

40 W. Du, Y. Gao, Q. Tian, D. Li, Z. Zhang, J. Guo and X. Qian, J. Nanopart. Res., 2015, 17, 1-12.

41 M. A. Peck and M. A. Langell, Chem. Mater., 2013, 24, 44834490.

42 K. Wang, Z. Zhang, X. Shi, H. Wang, Y. Lu and X. Ma, RSC Adv., 2014, 5, 1943-1948.

43 Y. Lei, J. Li, Y. Wang, L. Gu, Y. Chang, H. Yuan and D. Xiao, ACS Appl. Mater. Interfaces, 2014, 6, 1773-1780.

44 X. Leng, Y. Shao, L. Wu, S. Wei, Z. Jiang, G. Wang, Q. Jiang and J. Lian, J. Mater. Chem. A, 2016, 4, 10304-10313.

45 B. Babakhani and D. G. Ivey, Electrochim. Acta, 2011, 56, 4753-4762.

46 M. Li, J. P. Cheng, J. Wang, F. Liu and X. B. Zhang, Electrochim. Acta, 2016, 206, 108-115.

47 Y. Yang, M. Zhou, W. Guo, X. Cui, Y. Li, F. Liu, P. Xiao and Y. Zhang, Electrochim. Acta, 2015, 174, 246-253.

48 M. Li, J. P. Cheng, F. Liu and X. B. Zhang, Electrochim. Acta, 2015, 178, 439-446.

49 X. Liu, J. Zhao, Y. Cao, W. Li, Y. Sun, J. Lu, Y. Men and J. Hu, RSC Adv., 2015, 5, 47506-47510.

50 X. W. Wang, D. L. Zheng, P. Z. Yang, X. E. Wang, Q. Q. Zhu, P. F. Ma and L. Y. Sun, Chem. Phys. Lett., 2016, 667, 260-266.

51 X. W. Wang, Q. Q. Zhu, X. E. Wang, H. C. Zhang, J. J. Zhang and L. F. Wang, J. Alloys Compd., 2016, 675, 195-200.

52 X. W. Wang, X. E. Wang, H. C. Zhang, Q. Q. Zhu, D. L. Zheng and L. Y. Sun, Key Eng. Mater., 2017, 727, 698-704.

53 G. Zhang and X. W. Lou, Adv. Mater., 2013, 25, 976-979.

54 G. Zhang, W. Li, K. Xie, F. Yu and H. Huang, Adv. Funct. Mater., 2013, 23, 3675-3681.

55 S. Peng, L. Li, C. Li, H. Tan, R. Cai, H. Yu, S. Mhaisalkar, M. Srinivasan, S. Ramakrishna and Q. Yan, Chem. Commun., 2013, 49, 10178-10180.

56 M. Fan, B. Ren, L. Yu, D. Song, Q. Liu, J. Liu, J. Wang, X. Jing and L. Liu, Electrochim. Acta, 2015, 166, 168-173.

57 C. Yuan, X. Zhang, Q. Wu and G. Bo, Solid State Ionics, 2006, 177, 1237-1242.

58 Q. Y. Shan, X. L. Guo, F. Dong and Y. X. Zhang, Mater. Lett., 2017, 202, 103-106.

59 D. Du, Z. Hu, Y. Liu, Y. Deng and J. Liu, J. Alloys Compd., 2014, 589, 82-87.

60 H. Chen, J. Jiang, Y. Zhao, L. Zhang, D. Guo and D. Xia, J. Mater. Chem. A, 2014, 3, 428-437. 